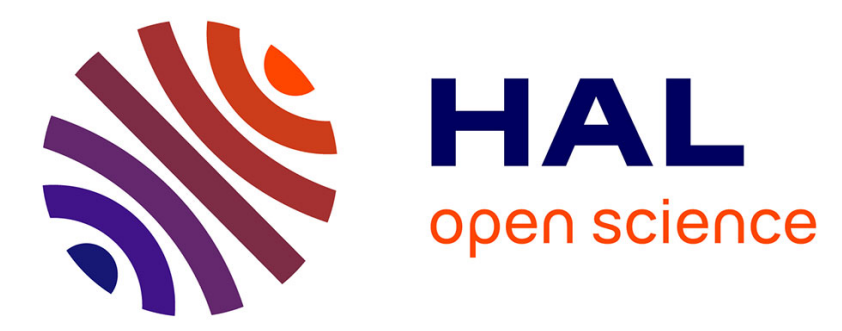

\title{
Comparison of direct and indirect genetic methods for estimating seed and pollen dispersal in Fagus sylvatica and Fagus crenata
}

\author{
Sylvie Sylvie Oddou-Muratorio, Aurore Bontemps, Etienne E. Klein, Igor \\ Chybicki, Giovanni Vendramin, Yoshihisa Suyama
}

\section{To cite this version:}

Sylvie Sylvie Oddou-Muratorio, Aurore Bontemps, Etienne E. Klein, Igor Chybicki, Giovanni Vendramin, et al.. Comparison of direct and indirect genetic methods for estimating seed and pollen dispersal in Fagus sylvatica and Fagus crenata. Forest Ecology and Management, 2010, 259, pp.21512159. hal-02656155

\section{HAL Id: hal-02656155 \\ https://hal.inrae.fr/hal-02656155}

Submitted on 29 May 2020

HAL is a multi-disciplinary open access archive for the deposit and dissemination of scientific research documents, whether they are published or not. The documents may come from teaching and research institutions in France or abroad, or from public or private research centers.
L'archive ouverte pluridisciplinaire HAL, est destinée au dépôt et à la diffusion de documents scientifiques de niveau recherche, publiés ou non, émanant des établissements d'enseignement et de recherche français ou étrangers, des laboratoires publics ou privés. 


\title{
Comparison of direct and indirect genetic methods for estimating seed and pollen dispersal in Fagus sylvatica and Fagus crenata
}

\author{
Sylvie Oddou-Muratorio ${ }^{\mathrm{a}, *}$, Aurore Bontemps $^{\mathrm{a}}$, Etienne K. Klein ${ }^{\mathrm{b}}$, Igor Chybickic ${ }^{\mathrm{c}}$, \\ Giovanni G. Vendramin ${ }^{\mathrm{d}}$, Yoshihisa Suyama ${ }^{\mathrm{e}}$ \\ a INRA UR 629, Ecologie des Forêts Méditerranéennes, Domaine St Paul, Site Agroparc, F-84914 Avignon, France \\ b INRA, UR 546, Biostatistique et Processus Spatiaux, Domaine St Paul, Site Agroparc, F-84914 Avignon, France \\ c Uniwersytet Kazimierza Wielkiego, Department of Genetics, Chodkiewicza 30, 85-064 Bydgoszcz, Poland \\ d CNR, Istituto di Genetica Vegetale, Via Madonna del Piano 10, I-50019 Sesto Fiorentino (Firenze), Italy \\ e Graduate School of Agricultural Science, Tohoku University, 232-3 Yomogida, Naruko-Onsen, Osaki, Miyagi 989-6711, Japan
}

\section{A R T I C L E I N F O}

\section{Article history:}

Received 1 February 2009

Received in revised form 17 February 2010

Accepted 1 March 2010

\section{Keywords:}

Parentage analyses

Neighbourhood model

Spatial genetic structure

Isolation by distance

Dispersal kernel

\begin{abstract}
A B S T R A C T
The comparison between estimates of historical gene flow, using variance in allelic frequencies, and estimates of contemporary gene flow, using parentage assignment, is expected to provide insights into ecological and evolutionary processes at work within and among populations. Genetic variation at microsatellite loci was used to quantify genetic structure in two wind pollinated, gravity and animaldispersed tree species (Fagus sylvatica L. and Fagus crenata Blum.) and to derive historical estimates of gene flow. The gene dispersal distances estimated assuming effective population density to be $1 / 4$ of the observed density were $\sim 77 \mathrm{~m}$ in European beech and $\sim 40 \mathrm{~m}$ in Japanese beech. Parentage analyses and a neighbourhood model approach were used to estimate contemporary patterns of seed and pollen dispersal. Our results suggest restricted seed dispersal abilities in both European beech $\left(\delta_{s}=10.5 \mathrm{~m}\right)$ and Japanese beech $\left(\delta_{s}=12.4 \mathrm{~m}\right)$, with an exponential shaped seed dispersal kernel. A non-negligible rate of seed immigration $\left(m_{s}=27 \%\right)$ was detected in European beech sites but not in Japanese beech site. Pollen dispersal within studied sites also appeared limited $\left(\delta_{p}=41.63 \mathrm{~m}\right.$ in European beech and $\delta_{p}=79.4 \mathrm{~m}$ in Japanese beech), despite high rate of pollen immigration $\left(m_{p}=68 \%\right.$ in European beech and $m_{p}=40 \% \mathrm{~m}$ in Japanese beech). Interestingly, contemporary and historical estimates of gene flow were within the same order of magnitude (a few tens of meters).
\end{abstract}

(C) 2010 Elsevier B.V. All rights reserved.

\section{Introduction}

The impact of predicted climatic changes on forest ecosystems is expected to be acute, resulting in notable changes in species' ranges, ecosystem function and species interactions. Because trees are long-lived they can disappear, disperse to other places or adapt in situ to climate change over a few generations. For several tree species bioclimatic models predict geographical shifts in the range of suitable habitat of several hundreds of kilometers by 2100 (without altitudinal compensation, Jump et al., 2009). The range of European beech (Fagus sylvatica $\mathrm{L}$.) for example is predicted to strongly contract in the west while expanding northwards, due to inadequate chilling in the west as winter warms more than summer (Sykes et al., 1996). These important predicted distribution shifts partly account for the intense research effort dedicated

\footnotetext{
* Corresponding author. Tel.: +33 432722 904; fax: +33 432722902

E-mail address: oddou@avignon.inra.fr (S. Oddou-Muratorio).
}

to species dispersal in recent decades (Bullock and Nathan, 2008; Ronce, 2007).

A primary concern in plants is whether seed dispersal capacities will allow species to track 21 st-century global warming. Analyses of paleoecological records are classically interpreted to suggest that tree populations are capable of rapid migration when climate warms, with rates of range expansion as high as $1000 \mathrm{~m} / \mathrm{year}$ during the early Holocene. Such a fast migration rate is possible by rare long-distance migration events (Clark, 1998) or by high latitude refugia reseeding the landscape (McLachlan et al., 2005). The latter means that post-glacial recolonisation may have been as much as an order of magnitude slower than previously thought $(<100 \mathrm{~m} /$ year). Another major issue related to plant dispersal is whether gene migration either through pollen or seeds can support local adaptation to changing climatic conditions by mixing or adding well adapted genetic material to poorly adapted gene pools (Davis and Shaw, 2001). The impact of migration on local adaptation depends on other important biological parameters (genetic effects, life cycle, mating system), and is complicated to predict when real- 
istic population demography estimates are included (Lenormand, 2002). For instance, while gene flow tends to oppose the effects of local selection and thus limits adaptation, intermediate rates of migration have been advocated to be optimal for local adaptation in low density populations at the range margin (Alleaume-Benharira et al., 2006). A more dynamic view of distribution ranges is now emerging in the literature which accounts for demographic and evolutionary processes associated to species expansions and retraction, and to marginal populations (Hampe and Petit, 2005).

Thus it is clear that predicting populations' responses to ongoing climate change requires fine characterisation of individual and gene dispersal processes at local, ecological scales as well as large, species-range scales. A way to address this issue is to use the rich toolbox available to estimate pollen and seed dispersal from genotype data at these different scales (Manel et al., 2005; Smouse and Sork, 2004). The most indirect approaches estimate historical dispersal parameters from the observed genetic structure by fitting them to theoretical population models generally assuming driftmigration equilibrium. By contrast, the most direct approaches use genetic markers to monitor contemporary movements of individuals or propagules by reconstructing parentage relationships (Manel et al., 2005), as in paternity/parentage analyses which are model-free beyond assuming Mendelian inheritance of the markers.

Indirect approaches to assess historical gene flow within continuous populations employ the principle that spatial genetic structure (SGS) displayed by neutral markers is essentially caused by local genetic drift, the effect of which is counterbalanced by gene dispersal. Under this isolation by distance model, the decay rate of genetic relatedness between individuals with distance has been shown to be inversely proportional to $d_{\mathrm{e}} \sigma_{\mathrm{e}}^{2}$, with $\sigma_{\mathrm{e}}^{2}$ equal to half of the mean-squared parent-offspring distance and $d_{\mathrm{e}}$ equal to the effective density of individuals (Rousset, 2000). Intuitively, the product $d_{\mathrm{e}} \sigma_{\mathrm{e}}^{2}$ expresses the degree of overlap between individual "gene shadows" (the spatial distribution of gene dispersal events around each parent). It implies that the intensity of genetic structuring decreases both with increasing dispersal and increasing individual density. Assuming that the genetic markers used in these analyses are not affected by natural selection, the summary parameter $d_{\mathrm{e}} \sigma_{\mathrm{e}}^{2}$ reflects the importance of both gene flow and genetic drift in shaping local differentiation on a historical time-scale. When reliable estimate of effective population size is available refined methods have been proposed to estimate the gene dispersal distance $\sigma_{\mathrm{e}}$ from patterns of SGS (Vekemans and Hardy, 2004).

Alternatively, patterns of contemporary gene flow between the parental and offspring cohorts can be estimated by using genetic fingerprint and parentage analyses to assign seedlings to their parent trees (parentage inference), and to infer the pollen and seed dispersal curves (Oddou-Muratorio and Klein, 2008). In the case of plant populations, parentage analysis consists of genotyping a sample of dispersed seeds or established seedlings and all the reproductive plants within a circumscribed area for a set of shared polymorphic markers to detect the parent pair of each seedling (Meagher, 1986). To discriminate between male and female parentage of seed and seedlings, one can genotype maternally inherited tissues collected on dispersed seeds (Jones et al., 2005; Jordano et al., 2007). When dealing with established seedlings, where purely maternal tissues are no longer available, average effective pollen/seed dispersal distance can be directly estimated from parent-offspring genotype data using model fitting, such as the neighbourhood model (Burczyk et al., 2006). These spatially explicit mating models have gained a broad acceptance among population geneticists and ecologists because they allow characterisation the seed and pollen dispersal processes and the heterogeneity in male/female fertility at an ecological time-scale (Burczyk et al., 2006; Morgan and Conner, 2001), as well as the ecological factors that are likely to influence these patterns, such as parental phenotypic traits (Gonzalez-Martinez et al., 2006), seed disperser behaviour (Jordano et al., 2007), or spatial environmental heterogeneity (Jones et al., 2005).

The comparison of historical versus contemporary estimates of gene flow is expected to provide interesting insights into the balance between and the time-scale of evolutionary forces at work within and among populations (Oddou-Muratorio and Klein, 2008). It has been argued that in undisturbed populations the consistency between historical and contemporary estimates of gene flow supports the drift-migration equilibrium hypothesis (Dunphy and Hamrick, 2005; Otero-Arnaiz et al., 2005), while divergence among real-time and effective migration rates has been used to highlight the consequence of sex-biased dispersal and social structure in small mammal species (Schweizer et al., 2007). In very recently disturbed populations, only contemporary estimates of gene flow should be affected because of temporal inertia of historical estimates for few (<10) generations (Leblois et al., 2004); the discrepancy among historical and contemporary estimates is thus expected to reflect the magnitude of the perturbation (Dutech et al., 2005). By contrast, consistent contemporary and historical estimates of gene flow in a recently perturbed area may indicate that compensatory mechanisms allow the maintenance of gene movement (Bacles et al., 2005).

European and Japanese beech (resp. F. sylvatica L. and Fagus crenata Blum.) are two related, deciduous, broad-leaved tree species that cover large portions of Europe and Japan, where they tend to grow in high-density stands. Despite the high economic and ecological importance of forests dominated by European or Japanese beech, the processes shaping their ecological and evolutionary response in face of global changes are only starting to be understood. In particular, contemporary pollen and seed dispersal patterns in beech have begun to be studied only recently (Kramer et al., 2008), showing that $90 \%$ of seeds disperse within $25 \mathrm{~m}$. Patterns of SGS show a tendency for strong family structure up to $30-40 \mathrm{~m}$, which suggests restricted migration rates of both pollen and seeds (Chybicki et al., 2009; Jump and Penuelas, 2007; Leonardi and Menozzi, 1996; Vornam et al., 2004). However, to our knowledge, the most recent available methods to estimate contemporary patterns of gene flow in these species have not been used, and historical and contemporary estimates have not been compared to date.

In the present study, we applied direct and indirect approaches to investigate both patterns of contemporary and historical gene flow in 4 sites ( 3 for European beech and 1 for Japanese beech). This study has several objectives: (1) to provide robust historical estimates of gene dispersal distance $\sigma_{\mathrm{e}}$ based on SGS, and contemporary estimates of seed and pollen dispersal based on spatially explicit mating models in European and Japanese beech; (2) based on these estimates to investigate variation in the estimated dispersal abilities between sites (for European beech) and species; and (3) to compare historical and contemporary estimates of dispersal within each site, with regard to the statistical specificities of both estimates and the expected effects of recent population demography within and among sites. Based on previous studies of SGS in beech, we expect rather restricted contemporary estimates of dispersal abilities in beech. However, pollen dispersal abilities are usually assumed important in wind-pollinated tree species. Also, our sampling design include recently disturbed forest stands, in which discrepancies between contemporary and historical gene flow estimates are susceptible to arise. Confronting contemporary and historical dispersal estimates will thus allow us to investigate how pollen and seed mediated gene flow respectively shape patterns of SGS in beech. 
Table 1

Information on study sites for each species.

\begin{tabular}{|c|c|c|c|c|c|c|}
\hline \multirow{2}{*}{$\begin{array}{l}\text { Species } \\
\text { Fagus sylvatica }\end{array}$} & \multirow{2}{*}{$\begin{array}{l}\text { Site } \\
\text { FS1 (Mont Ventoux) }\end{array}$} & \multicolumn{2}{|c|}{ Coordinates (UTM) } & \multirow{2}{*}{$\begin{array}{l}\begin{array}{l}\text { Number of } \\
\text { genotyped adults }\end{array} \\
96\end{array}$} & \multirow{2}{*}{$\begin{array}{l}\begin{array}{l}\text { Observed adult } \\
\text { density (tree ha-1) }\end{array} \\
50\end{array}$} & \multirow{2}{*}{$\begin{array}{l}\text { Number of } \\
\text { genotyped seedlings } \\
256\end{array}$} \\
\hline & & $44^{\circ} 10^{\prime} 45^{\prime \prime} \mathrm{N}$ & $5^{\circ} 14^{\prime} 01^{\prime \prime} \mathrm{E}$ & & & \\
\hline Fagus sylvatica & FS2 (Mont Ventoux) & $44^{\circ} 11^{\prime} 03^{\prime \prime} \mathrm{N}$ & $5^{\circ} 16^{\prime} 57^{\prime \prime} \mathrm{E}$ & 50 & 19 & 356 \\
\hline Fagus sylvatica & FS3 (Haye Forest) & $48^{\circ} 45^{\prime} 30^{\prime \prime} \mathrm{N}$ & $6^{\circ} 20^{\prime} 29^{\prime \prime} \mathrm{E}$ & 350 & 44 & 221 \\
\hline Fagus crenata & FC (Kurokima) & $38^{\circ} 55^{\prime} 30^{\prime \prime} \mathrm{N}$ & $140^{\circ} 47^{\prime} 50^{\prime \prime} \mathrm{E}$ & 287 & 379 & 1387 \\
\hline
\end{tabular}

\section{Materials and methods}

\subsection{Studied species and sampling design}

European and Japanese beech are described as highly outcrossing wind-pollinated trees (Asuka et al., 2005; Hanaoka et al., 2007; Merzeau et al., 1994). Reproductive trees (typically older than 40-50 years) produce beech nuts in irregular mast years (with an average interval between mast years of $\sim 5$ or $\sim 7$ years; Tomita et al., 2002). Mature seed dissemination begins in September, primarily through gravity and secondarily assisted by various animals including rodents such as voles and wood mice that have been reported to scatter-hoard seeds (Jensen, 1985).

For European beech three plots were studied within two different locations (Table 1). FS1 and FS2 are located on Mont Ventoux, South-Eastern France, where an expanding population of European beech mixed with Abies alba is recolonising a pine forest (Bontemps et al., unpublished). FS3 is located in the ancient Haye Forest, NorthEastern France (Oddou-Muratorio et al., unpublished). Within each plot, adult trees (i.e. with diameter $>10 \mathrm{~cm}$ or producing seeds) were exhaustively mapped (Table 1 ) and their diameter was measured (Fig. 1). Within each site, both seedlings (seedlings, age $<3$ years) and saplings ( $<1 \mathrm{~m}$ high, app. younger than 20 years, roughly estimated from scars counts) were sampled non-exhaustively, and mapped (Fig. 1).

For Japanese beech, the $170 \mathrm{~m} \times 170 \mathrm{~m}$ study plot was located in a primary beech forest in northern Japan on the southern foot of Mt Kurokima (see also Takahashi et al., 2000). All of the 287 adult trees were sampled, mapped, and their diameter was measured (Fig. 1). 1387 seedlings emerged in 2001 and were also mapped and sampled.

\subsection{Genotyping}

All Japanese beech individuals were genotyped at 7 highly variable microsatellite markers (Table 2), while in European beech, all individuals were genotyped at a set of either 5 (FS3) or 11 (FS1 and FS2) microsatellite markers (Asuka et al., 2004; Pastorelli et al., 2003; Tanaka et al., 1999).

\section{FS2}
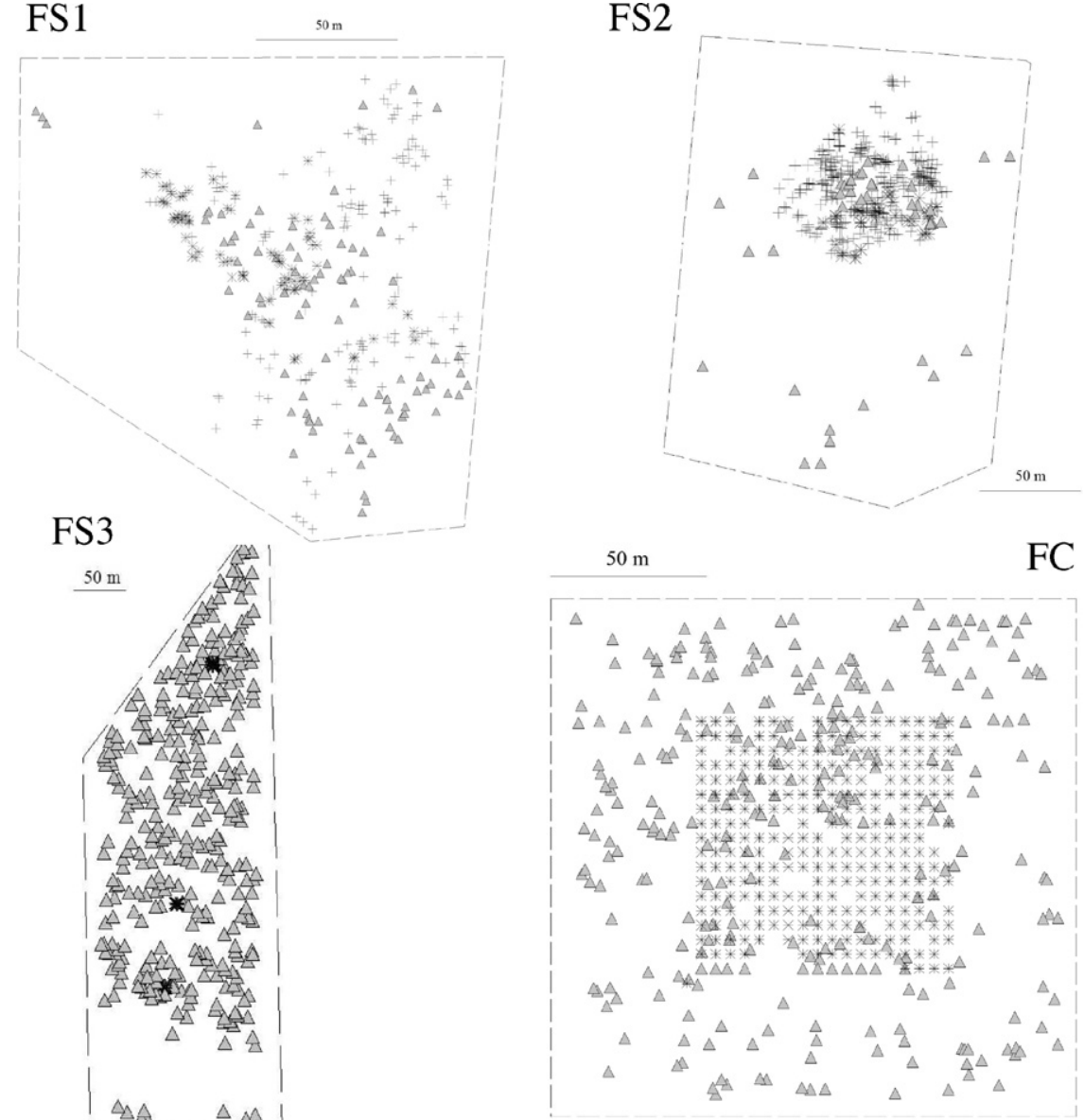

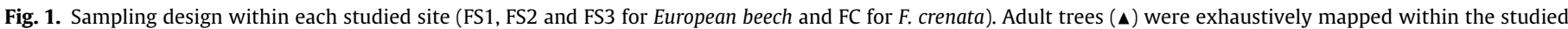
site. Saplings $\left(+\right.$, age $\geq 3$ ) and/or seedlings $\left({ }^{*}\right.$, age $\left.<3\right)$ were sampled preferentially in the central part of studied site. 
Table 2

Number of alleles ( $\mathrm{Na}$ ) and null allele frequencies (Fnull) per species, site and microsatellite locus.

\begin{tabular}{|c|c|c|c|c|c|c|c|c|}
\hline \multirow{3}{*}{$\begin{array}{l}\text { Species } \\
\text { Site } \\
\text { Locus }\end{array}$} & \multicolumn{6}{|c|}{ Fagus sylvatica } & \multirow{2}{*}{\multicolumn{2}{|c|}{$\begin{array}{l}\text { Fagus crenata } \\
\text { FC }\end{array}$}} \\
\hline & \multicolumn{2}{|l|}{ FS1 } & \multicolumn{2}{|c|}{$\mathrm{FS} 2$} & \multicolumn{2}{|l|}{ FS3 } & & \\
\hline & $\mathrm{Na}$ & Fnull & $\mathrm{Na}$ & Fnull & $\mathrm{Na}$ & Fnull & $\mathrm{Na}$ & Fnull \\
\hline $\mathrm{FS} 1-03 \mathrm{a}^{\mathrm{a}}$ & & & & & & & 17 & 0.000 \\
\hline $\mathrm{FS} 1 \_15^{\mathrm{a}}$ & 13 & 0.037 & 14 & 0.006 & & & & \\
\hline FS4-46 a & & & & & 24 & 0.094 & 14 & 0.000 \\
\hline FS3-04 a & 3 & 0.000 & 4 & 0.000 & 5 & 0.000 & & \\
\hline $\operatorname{mfc} 5^{b}$ & & & & & 24 & 0.084 & & \\
\hline $\operatorname{mfc} 7^{b}$ & 7 & 0.057 & 7 & 0.058 & & & & \\
\hline $\operatorname{sfc} 0007^{c}$ & 7 & 0.000 & 8 & 0.019 & & & & \\
\hline $\operatorname{sfc} 1105^{c}$ & 14 & 0.000 & 9 & 0.031 & & & 33 & 0.002 \\
\hline $\operatorname{sfc} 1143^{c}$ & 12 & 0.012 & 11 & 0.000 & & & 23 & 0.000 \\
\hline $\operatorname{sfc} 0036^{c}$ & 10 & 0.000 & 11 & 0.000 & & & 24 & 0.000 \\
\hline $\operatorname{sfc0018^{c}}$ & 9 & 0.006 & 11 & 0.013 & & & 19 & 0.002 \\
\hline $\operatorname{sfc} 0378^{c}$ & & & & & & & 27 & 0.010 \\
\hline $\operatorname{sfc} 0161^{c}$ & 14 & 0.003 & 14 & 0.000 & 18 & 0.000 & & \\
\hline sfc1063 c & 10 & 0.125 & 8 & 0.107 & & & & \\
\hline $\operatorname{mfs} 11^{d}$ & 8 & 0.103 & 9 & 0.045 & & & & \\
\hline
\end{tabular}

Detailed information on microsatellite loci can be found in:

a Pastorelli et al. (2003).

b Tanaka et al. (1999).

c Asuka et al. (2004).

d Vornam et al. (2004).

High prevalence of null alleles has been reported for microsatellite markers developed for European beech (Chybicki and Burczyk, 2009; Oddou-Muratorio et al., 2009). Therefore, we carefully checked for presence of null alleles both in adult and seedling cohorts using the maximum-likelihood method accounting for genotyping error implemented in ML-NullFreq (Kalinowski and Taper, 2006).

\subsection{SGS and historical estimates of gene flow}

SGS was characterised by analysing variation of genetic relatedness, as measured by the kinship coefficient $\left(F_{i j}\right)$ of Loiselle et al. (1995), as function of the logarithm of geographic distance $d_{i j}$ between every pair of adults/seedlings $i$ and $j$.

To visualize SGS, $F_{i j}$ values were averaged over a set of distance classes $(d)$, and plotted against the logarithm of the distance. Approximate standard errors for the multilocus estimates of $F_{i j}$ within each distance class were obtained through a jackknife procedure that consisted of deleting each locus one at a time. This assumes that the different loci provide independent replicates of the genetic structure process. To test SGS, the $F_{i j}$ values were regressed on $\ln \left(d_{i j}\right)$, where $d_{i j}$ is the spatial distance between individuals $i$ and $j$, to provide the regression slope $b$. Then, the spatial positions of the individuals were permuted 5000 times in order to get the frequency distribution of $b$ under the null hypothesis that $F_{i j}$ and $d_{i j}$ were uncorrelated. Following Vekemans and Hardy (2004), the SGS intensity was quantified by $S p=b /\left(F_{1}-1\right)$, where $F_{1}$ is the average kinship coefficient between individuals of the first distance class $(<50 \mathrm{~m})$.

An indirect estimate of the product $d_{\mathrm{e}} \sigma_{\mathrm{e}}^{2}$, where $d_{\mathrm{e}}$ is the effective population density, was obtained through:

$d_{\mathrm{e}} \sigma_{\mathrm{e}}^{2}=-\frac{1-F_{N}}{4 \Pi b}$

where $F_{N}$ is the kinship coefficient between neighbouring individuals, estimated here by $F_{1}$ (Rousset, 2000). Ideally, $b$ should be computed as the restricted regression slope of $F_{i j}$ on $\ln \left(d_{i j}\right)$ in the range $\sigma_{\mathrm{e}}>d_{i j}>20 \sigma_{\mathrm{e}}$ for relationship (1) to be valid. However, in most data sets investigated here the iterative procedure required for estimating this restricted regression slope failed to converge. Therefore, all results reported here were based on regression over the whole range of geographical distances between individuals. All computations were performed with the SPAGeDi software (Hardy and Vekemans, 2002).

\subsection{Neighbourhood model and contemporary estimates of gene flow}

We used a slightly modified version of the neighbourhood mating model described in Burczyk et al. (2006), where all potential parents are encapsulated within a single neighbourhood corresponding to the study site (Oddou-Muratorio and Klein, 2008). We assumed that each sampled seedling $i$ could be mothered either (1) by a mother tree located outside the study site due to seed immigration (with probability $m_{s}$ ) or (2) by a mother tree located within the studied site (with probability $\left(1-m_{s}\right)$ ). In the latter case offspring $i$ may be the result of self-pollination (with probability $s$ ), pollen flow from outside the study site (with probability $m_{p}$ ), or pollen from a sampled male (with probability $1-s-m_{p}$ ). The probability of observing a multilocus diploid genotype $G_{i}$ among the seedlings is thus:

$$
\begin{aligned}
P\left(G_{i}\right)= & m_{s} T\left(G_{i} \mid \mathrm{BAF}\right)+\left(1-m_{s}\right) \sum_{j \in \mathrm{ISP}} \Psi_{i j}\left[s T\left(G_{i} \mid M_{j}, M_{j}\right)\right. \\
& \left.+m_{p} T\left(G_{i} \mid M_{j}, \mathrm{BAF}\right)+\left(1-s-m_{p}\right) \sum_{k \in \mathrm{ISP}} \Phi_{j, k} T\left(G_{i} \mid M_{j}, F_{k}\right)\right]
\end{aligned}
$$

where $T\left(G_{i} \mid \mathrm{BAF}\right)$ is the transition probability that an offspring immigrating from a mother tree located outside of the study site has genotype $G_{i}$ knowing the Background Allelic Frequencies (BAF); $T\left(G_{i} \mid M_{j}, M_{j}\right), T\left(G_{i} \mid M_{j}\right.$, BAF), $T\left(G_{i} \mid M_{j}, F_{k}\right)$ are the transition probabilities that an offspring has diploid genotype $G_{i}$ when its mother tree of genotype $M_{j}$ is respectively (1) self-pollinated (2) pollinated by a father drawn at random in a population with allelic frequencies BAF or (3) pollinated by a father of genotype $F_{k}$.

Parameter $\psi_{i, j}$ is the proportion of seeds from mother tree $j$ at the location of seedling $i$ among the virtual seed pool originating from all known mother trees from the neighbourhood $N$ :

$\Psi_{i j}=\frac{\tau_{i j}}{\sum_{l \in N} \tau_{i l}}$ 
where $\tau_{i j}$ is a function of one or more factors influencing female reproductive success, including the seed dispersal kernel (see below).

Parameter $\Phi_{j k}$ is the proportion of pollen from tree $k$ in the pollen pool of mother tree $j$ in the total pollen pool from the known father trees in the neighbourhood $N$ :

$\Phi_{j k}=\frac{\pi_{j k}}{\sum_{l \in N} \pi_{j l}}$

where $\pi_{j k}$ is a function of one or more factors influencing male reproductive success, including the pollen dispersal kernel (see below).

\subsubsection{Models for pollen and seed dispersal kernel}

As in Oddou-Muratorio et al. (2005), pollen dispersal was modelled using a dispersal kernel $p_{p}(. ; x, y)$ describing the probability for a pollen grain emitted at position $(0,0)$ to participate to the pollen cloud at position $(x, y)$. Following this scheme, we modelled seed dispersal using a dispersal kernel $p_{s}(. ; x, y)$ describing the probability for a seed emitted at position $(0,0)$ to establish as a seedling at position $(x, y)$. We considered here the family of exponential-power functions:

$p(a, b ; x, y)=\frac{b}{2 \pi a^{2} \Gamma(2 / b)} \exp \left(-\left(\frac{\sqrt{x^{2}+y^{2}}}{a}\right)^{b}\right)$,

where $\Gamma$ is the classically defined gamma function (Abramowitz and Stegun, 1964). The parameter $b$ is the shape parameter affecting the tail of the dispersal function and $a$ is a scale parameter homogeneous to distance. The mean distance $(\delta)$ traveled by a pollen grain/seed under the kernel $p(a, b ;$.$) and the$ root-mean-square axial distance are given by Austerlitz et al. (2004):

$\delta=a \frac{\Gamma(3 / b)}{\Gamma(2 / b)}$ and $\sigma=a \sqrt{\frac{\Gamma(4 / b)}{2 \Gamma(2 / b)}}$

Both increase with $a$ and decrease with $b$. When $b<1$, the dispersal kernel is fat-tailed (Clark, 1998), i.e. the long-range decrease is slow, increasing the probability of long-distance dispersal events. Conversely, when $b>1$ (for instance the Gaussian model, for which $b=2$ ) the dispersal is thin-tailed, with a rapid decrease of the dispersal function, implying fewer long-distance dispersal events than when $b<1$.

Model for female/male reproductive success (the $\tau_{i j}$ 's and the $\pi_{j k}$ 's): individual female reproductive success $\tau_{i j}$ of female $j$ on seedlings location $i$ was determined by two kind of factors interacting multiplicatively: (1) the distance of seedling $i$ from mother $j$ through the dispersal kernel described above and (2) adult tree diameter as a surrogate for female fecundity. Here $\tau_{i j}$ is expressed as follows:

$\tau_{i j}=e^{\gamma_{\mathrm{f}} D_{j}} \times p_{s}\left(a_{s}, b_{s} ; x_{i}-x_{j}, y_{i}-y_{j}\right)$

where $D_{j}$ is the diameter of mother $j$, and $a_{s}$ and $b_{s}$ the parameters of the seed dispersal kernel $p_{s}$ described by Eq. (5). Classically, we chose an exponential function of parameter $\gamma_{\mathrm{f}}$ to relate the fecundity surrogate (here $D_{j}$ ) to reproductive success because it assures a positive value for the reproductive success parameter. Additionally, this model of the selection gradient is well-suited for a continuously distributed variable such as diameter.

Individual male reproductive success $\pi_{j k}$ of tree $k$ in the local pollen cloud of mother $j$ depended on two independent factors: (1) the distance of mother $j$ to father $k$ and the pollen dispersal parameters and (2) the diameter of tree $k$ as a surrogate for male
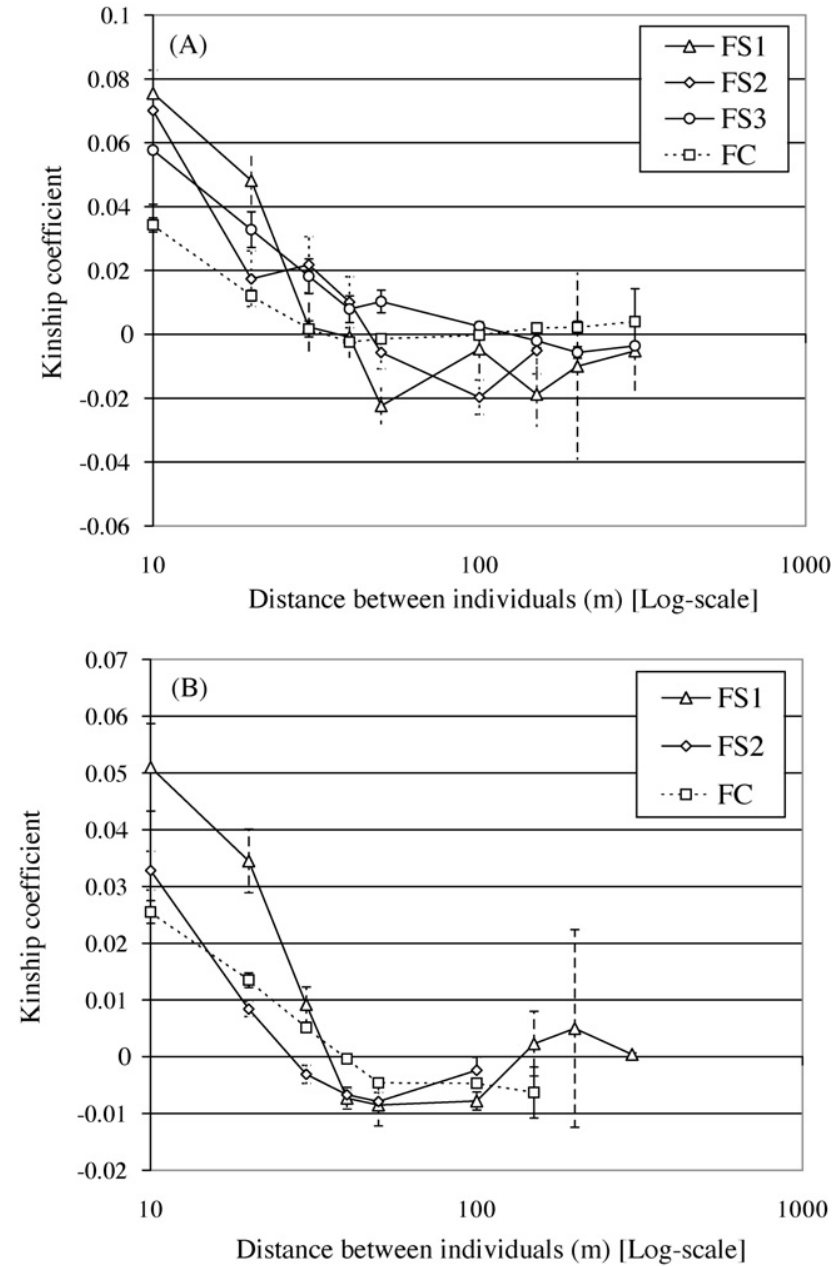

Fig. 2. Correlograms of kinship coefficient for (A) adult trees and (B) seedlings in the four sites. Abscise values correspond to the upper limit of the distance intervals Filled symbols represent values significantly different from the expected value under a random distribution of genotypes (95\% confidence level). Confidence intervals around each $F_{i j}$ value were obtained through a jackknife procedure over loci.

fecundity. Therefore, $\pi_{j k}$ was expressed as follows:

$\pi_{j k}=e^{\gamma_{\mathrm{m}} D_{k}} \times p_{p}\left(a_{p}, b_{p} x_{j}-x_{k}, y_{j}-y_{k}\right)$

where $D_{k}$ is the diameter of father $k, \gamma_{\mathrm{m}}$ is the male fecundity parameter, and $a_{p}$ and $b_{p}$ are the parameters of the pollen dispersal kernel $p_{p}$.

\subsubsection{Parameters inference}

We obtained maximum-likelihood estimates for the seed and pollen immigration rates $\left(m_{s}\right.$ and $\left.m_{p}\right)$, selfing rate $(s)$, kernel parameters ( $a_{s}$ and $b_{s}$ for seed dispersal kernel; $a_{p}$ and $b_{p}$ for pollen dispersal kernel) and contextual gradients $\left(\gamma_{\mathrm{f}}\right.$ and $\left.\gamma_{\mathrm{m}}\right)$, by maximising the log-likelihood functions:

$\log L\left(a_{p}, b_{p}, a_{s}, b_{s}, s, m_{p}, m_{s}, \gamma_{\mathrm{f}}, \gamma_{\mathrm{m}}\right)=\sum_{i=1}^{S} \log \left[P\left(G_{i}\right)\right]$

where $S$ is the total number of genotyped seedlings.

Parameters were fitted with the Newton-Raphson algorithm using NM+ software (Chybicki and Burczyk unpublished). NM+ allowed us to estimate simultaneously the frequencies of null alleles at each marker, and to eliminate markers significantly affected by null alleles (i.e. with frequency of null alleles $>0.10$ ). 
Table 3

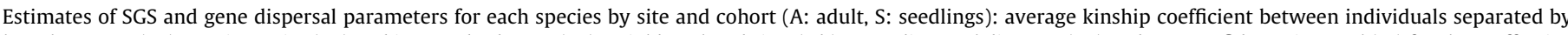

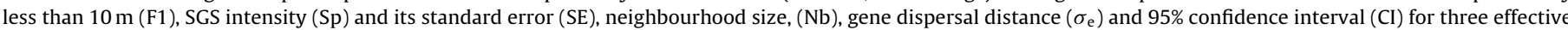
densities $\left(d_{\mathrm{e}}\right)$ estimated from the density of adults $(D)$

\begin{tabular}{|c|c|c|c|c|c|c|c|c|}
\hline \multirow[t]{2}{*}{ Species } & \multirow[t]{2}{*}{ Site } & \multirow[t]{2}{*}{ Stage } & \multicolumn{2}{|c|}{ SGS parameter } & \multicolumn{4}{|c|}{ Gene dispersal parameters } \\
\hline & & & $\mathrm{F} 1$ & $\mathrm{Sp}(\mathrm{SE})$ & $\mathrm{Nb}$ & $\sigma_{\mathrm{e}}(\mathrm{CI}) d_{\mathrm{e}}=D / 2$ & $\sigma_{\mathrm{e}}(\mathrm{CI}) d_{\mathrm{e}}=D / 4$ & $\sigma_{\mathrm{e}}(\mathrm{CI}) d_{\mathrm{e}}=D / 10$ \\
\hline \multirow{5}{*}{ Fagus sylvatica } & FS1 & A & 0.0821 & $0.0218(0.0046)$ & 45.80 & $31.36(26.2-41.5)$ & 44.35 (37.1-58.7) & $70.12(58.7-92.8)$ \\
\hline & & $S$ & 0.0328 & $0.0163(0.0018)$ & 61.43 & $40.62(36.3-47)$ & $57.44(51.3-66.4)$ & $90.82(81.2-105)$ \\
\hline & $\mathrm{FS} 2$ & A & 0.0785 & $0.0354(0.0076)$ & 28.22 & $64.69(54.3-84.7)$ & $91.48(76.8-119.8)$ & $144.64(121.5-189.4)$ \\
\hline & & $S$ & 0.051 & $0.0205(0.0026)$ & 48.76 & $72.98(66-82.9)$ & $103.21(93.3-117.2)$ & $163.19(147.5-185.3)$ \\
\hline & FS3 & A & 0.0577 & $0.0087(0.0012)$ & 114.33 & $65.97(58.4-77.4)$ & $93.30(82.6-109.5)$ & $147.52(130.7-173.2)$ \\
\hline \multirow[t]{2}{*}{ Fagus crenata } & FC & A & 0.0343 & $0.0032(0.0007)$ & 312.15 & $36.84(30.6-49.8)$ & $52.10(43.2-70.4)$ & $82.38(68.4-111.3)$ \\
\hline & & $S$ & 0.0255 & $0.0124(0.0012)$ & 80.67 & $18.64(17.1-20.7)$ & $26.37(24.2-29.3)$ & $41.69(38.2-46.4)$ \\
\hline
\end{tabular}

\section{Results}

\subsection{Genetic markers and null alleles}

The frequency of null alleles was overall lower in the Japanese beech data set than in any of the three European beech data sets (Table 2). Frequencies of null alleles ranged from 0 (in 12 site/loci combination out of 33) to 0.125 .

\subsection{SGS and historical estimates}

SGS was significant in the four data sets, with both adults and seedlings more related than expected by chance for distances up to $30-40 \mathrm{~m}$ (Fig. 2). The strength of SGS, as depicted by the Sp-statistics, significantly differed among sites: the ancient Japanese beech stand showed the weakest pattern of SGS ( $S \mathrm{P}_{\mathrm{FC}}=0.0032$ in adults), followed by the ancient European beech stand $\left(\mathrm{Sp}_{\mathrm{FS} 3}=0.0087 \mathrm{in}\right.$ adults $)$, then by the high-density recolonising European beech stand ( $\mathrm{Sp}_{\mathrm{FS} 1}=0.0218$ in adults), and finally by the low-density recolonising European beech stand $\left(\mathrm{Sp}_{\mathrm{FS} 2}=0.0354\right.$ in adults). Within site, stronger SGS was detected in adults compared to seedlings in the recolonising European beech stand FS1 (FS1: $S p_{A}=0.0218$ versus $S p_{S}=0.0163$, Table 3 ) while in FS2 SGS did not differ among adults and seedlings $\left(S p_{A}=0.0354\right.$ versus $S p_{S}=0.0205$ ). In mature populations of Japanese beech, SGS was significantly weaker among adults compared to seedlings (FS1: $S p_{A}=0.0032$ versus $\left.S p_{S}=0.0124\right)$. In FS3, the sampling design of seedlings did not allow estimation of SGS (Fig. 1).

Using observed density $d_{\text {obs }} / 2$ to estimate $d_{\mathrm{e}}$, SGS converted into axial variance of gene dispersal $\left(\sigma_{\mathrm{e}}\right)$ between $31 \mathrm{~m}$ (adult, FS2) and $73 \mathrm{~m}$ (seedlings, FS2, Table 3 ) for the European beech, and between $19 \mathrm{~m}$ (seedlings) and $37 \mathrm{~m}$ (adult) for the Japanese beech.
Fixing $d_{\mathrm{e}}=d_{\mathrm{obs}} / 10, \sigma_{\mathrm{e}}$ increased markedly, ranging between 70 and $163 \mathrm{~m}$ for the European beech and between 42 and $82 \mathrm{~m}$ for the Japanese beech. In Japanese beech, $\sigma_{\mathrm{e}-\text { seedlings }}<\sigma_{\mathrm{e} \text {-sadults }}$ whatever the assumed $d_{\mathrm{e}} / d_{\mathrm{obs}}$ ratio (Table 3 ).

\subsection{Neighbourhood model and contemporary estimates}

Direct estimates of mating and dispersal parameters are summarised in Table 4. For these analyses, the marker sfc1063 was removed due to high frequency of null alleles (up to 12.5\%). For the European beech, important seed migration $\left(21 \%<m_{s}<36 \%\right)$ and very high pollen migration $\left(63 \%<m_{p}<72 \%\right)$ from outside the studied site were detected. In the Japanese beech by contrast, seed immigration rate was not different from zero, and pollen immigration rate was estimated to be $40 \%$.

The average distance of seed dispersal within the study site fell within the same order of magnitude across sites and species with $\delta_{s}=10.5 \mathrm{~m}$ (for European beech on average on FS1 and FS3) and $\delta_{s}=12.4 \mathrm{~m}$ (for Japanese beech). Average distance of pollen dispersal was also not significantly different among species and sites with $\delta_{p}=38 \mathrm{~m}$ on average in European beech and $\delta_{p}=79 \mathrm{~m}$ in Japanese beech. Some of the estimated values for $\delta_{s}$ and $\delta_{p}$ suffered from low precision (large standard errors); this is an expected behaviour when the slope of the dispersal kernel $\left(b_{s}\right.$ and $\left.b_{p}\right)$ is well below 1 (Oddou-Muratorio et al., 2005). For both pollen and seed dispersal, we observed a general tendency of slightly fat-tailed dispersal kernels (i.e. $b \leq 1$ ). In FS3, the $b$-parameters could not be simultaneously estimated with the other parameters due to lack of convergence, but the best fits were obtained with an exponential kernel for seeds and pollen. The estimated seed dispersal kernel was exponential in FC, only slightly more fatter-tailed than the exponential in FS3 $\left(b_{s}=0.72\right)$, while it was strongly thin-tailed in

Table 4

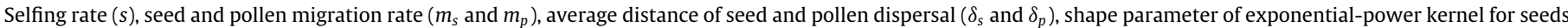

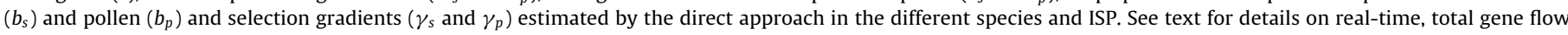
estimates $\left(\sigma_{r t}\right)$.

\begin{tabular}{|c|c|c|c|c|c|c|c|c|}
\hline \multirow{3}{*}{$\begin{array}{l}\text { Species } \\
\text { Site } \\
\text { Parameter }\end{array}$} & \multicolumn{6}{|c|}{ Fagus sylvatica } & \multirow{2}{*}{\multicolumn{2}{|c|}{$\begin{array}{l}\text { Fagus crenata } \\
\text { FC }\end{array}$}} \\
\hline & \multicolumn{2}{|l|}{ FS1 } & \multicolumn{2}{|l|}{ FS2 } & \multicolumn{2}{|l|}{ FS3 } & & \\
\hline & Estimate & SE & Estimate & SE & Estimate & SE & Estimate & SE \\
\hline$m_{s}$ & 0.23 & 0.03 & 0.36 & 0.04 & 0.21 & 0.04 & 0.007 & 0.0035 \\
\hline$m_{p}$ & 0.63 & 0.04 & 0.68 & 0.04 & 0.72 & 0.06 & 0.40 & 0.019 \\
\hline$s$ & 0.01 & 0.01 & 0.04 & 0.02 & 0.03 & 0.02 & $0.00^{\mathrm{a}}$ & $\mathrm{NE}$ \\
\hline$\delta_{s}(\mathrm{~m})$ & 10.42 & 1.39 & 62.42 & 73.68 & 10.89 & 0.90 & 12.14 & 0.36 \\
\hline$\delta_{p}(\mathrm{~m})$ & 28.12 & 4.39 & 30.52 & 18.56 & 55.14 & 17.99 & 79.04 & 30.88 \\
\hline$b_{s}$ & 0.72 & 0.15 & 0.15 & 0.10 & $1.00^{\mathrm{a}}$ & $\mathrm{NE}$ & 1.06 & 0.07 \\
\hline$b_{p}$ & 1.03 & 0.33 & 0.68 & 0.23 & $1.00^{\mathrm{a}}$ & $\mathrm{NE}$ & 0.30 & 0.07 \\
\hline$\gamma_{s}$ & 0.86 & 0.08 & & & & & 0.85 & 0.06 \\
\hline$\gamma_{p}$ & $0.60^{\mathrm{a}}$ & $\mathrm{NE}$ & & & & & 0.65 & 0.07 \\
\hline$\sigma_{r t}(\mathrm{~m})$ & 19.66 & & 142.61 & & 35.06 & & 71.21 & \\
\hline
\end{tabular}

NE: corresponding standard error not estimated.

a Fixed value for the parameter. 
FS2 $\left(b_{s}=0.15\right)$. For the pollen dispersal kernel the estimated shape ranged from 0.30 (FC) to 1.03 (FS1).

The effect of diameter on female and male fertility was highly significant, with both male and female fecundities increasing with diameter $\left(\gamma_{s}=0.86\right.$ and $\left.\gamma_{p}=0.62\right)$. The selection gradient tended to be steeper for female fecundity than for male fecundity. Selection gradients could not be estimated for FS3 (no data) or FS2 (due to lack of convergence).

\section{Discussion}

This study provided historical and contemporary estimates of gene flow in European and Japanese beech based on common, robust methods applied to four different parent-offspring genotype data sets. In the following we first discuss methodology related to each estimate (historical or contemporary) and investigate their variation in the observed range of species and sites. Finally, we discuss the implication of our results for the understanding of gene dispersal in beech, and the consequences for management of the genetic resources of this species.

\subsection{Patterns of SGS and historical estimates of gene flow}

In both European and Japanese beech seedlings and adults showed a significant pattern of SGS associated with historical dispersal rates ranging from $\sim 47$ to $\sim 105 \mathrm{~m}$ depending on the assumed ratio of effective versus observed density (respectively $1 / 2$ and $1 / 10$ ). For long-lived organisms such as trees it is notoriously difficult to estimate $d_{\mathrm{e}} / d_{\mathrm{obs}}$, or $N_{\mathrm{e}} / N$ (the ratio of effective versus census population size), as these quantities depend on the variation in lifetime reproductive success among individuals. Following Hardy et al. (2006) and assuming $d_{\mathrm{e}}=d_{\mathrm{obs}} / 4$ in our long-lived hermaphrodite tree species the estimated gene dispersal distances were $\sim 77 \mathrm{~m}$ in European beech and $\sim 40 \mathrm{~m}$ in Japanese beech. Despite a slightly lower $\sigma_{\mathrm{e}}$ estimate for the adults in FS1 $\left(\sigma_{\mathrm{eFS} 1}=44.35 \mathrm{~m}\right.$, significantly inferior to estimates from FS2 and FS3), gene dispersal distances were similar across sites and cohorts in European beech. Moreover, our results overall reflect a trend towards restricted dispersal abilities in beech compared to tropical (Hardy et al., 2006) or temperate, low-density (Oddou-Muratorio and Klein, 2008) tree species, where $\sigma_{\mathrm{e}}$ ranged from 150 to $1200 \mathrm{~m}$.

Interestingly, the comparison of SGS intensity between cohorts and between expanding and ancient populations highlights the interaction between population history, effective population density and dispersal in the development of SGS. First, the increasing SGS (and conversely decreasing $d_{\mathrm{e}} \sigma_{\mathrm{e}}$ product) observed from adult to seedlings in Japanese beech contrasted with the more similar SGS patterns observed among cohorts in European beech. The reduction in the $d_{\mathrm{e}} \sigma_{\mathrm{e}}$ product from adults to seedlings observed in the Japanese beech may be due to several causes: (1) a recent reduction in effective gene dispersal $\left(\sigma_{\mathrm{e}}\right),(2)$ a recent reduction in effective population density $\left(d_{\mathrm{e}}\right)$ in Japanese beech, and/or (3) a reduction of a substantial part of coancestry between nearest neighbours during stand maturation from seedlings to adults (Epperson, 1992). The fact that all the analysed Japanese beech seedlings correspond to a single year of reproduction (as compared to European beech seedlings, recruited across several year of reproduction) support hypothesis (2) above: single year $d_{\mathrm{e}}$ is indeed expected to be lower (due to high inter-individual variance in reproductive success) as compared to average $d_{\mathrm{e}}$ accumulated over several reproductive events (Krouchi et al., 2004).

Second, SGS was significantly weaker in ancient stands (FS3 and FC) compared to recolonising stands (FS1 and FS2). This variation was independent of observed adult density, as FS3 and FS1 showed roughly the same density (Table 1 ). Marked patterns of
SGS have also been found in recently founded populations (Parker et al., 2001). In our case, it is likely that the strongly spatially aggregated distribution of adults in FS1, compared to the more regular distribution in FS3 (Fig. 1), accounts for the higher intensity of SGS due to restricted overlap of seed shadows in FS1. By contrast, the higher SGS in FS2 compared to FS1 can be explained by the lower population density in FS2, which also reduces the seed shadow overlap.

\subsection{Contemporary estimates of seed and pollen dispersal}

Direct estimates of seed and pollen dispersal curves using the spatially explicit mating model also highlight restricted seed dispersal abilities in European and Japanese beech, despite non-negligible long-distance dispersal events, and potentially important pollen-mediated gene flow.

Considering first seed dispersal patterns within studied sites, seed dispersal distances were consistent across sites and species, with a mean $\delta_{s}$ value of $10.5 \mathrm{~m}$ for European beech and $12.4 \mathrm{~m}$ for Japanese beech. Moreover the best fits were obtained either with exponential or fat-tailed kernels. The different values obtained for seed dispersal parameters in site FS2 may be partially explained by the age distribution of seedlings, because old seedlings ( $>4$ years old) were over-represented in this site compared to the 3 other sites. Estimates of the seed dispersal parameter for the sub-sample of young seedlings in FS2 fell within the same order of magnitude as the 3 others ( $\delta_{s}=7.68$ and $b_{s}=1$, Bontemps et al., unpublished). Thus, the seed rain generated within a single or few reproductive events and observed at the early stage of seedling recruitment reflects rather restricted seed dispersal abilities in beech compared to other species where such estimates are available (e.g. $\delta_{s} \approx 135 \mathrm{~m}$ in S. torminalis, Oddou-Muratorio and Klein, 2008); $\left(\delta_{s}=277 \mathrm{~m}\right.$ in Prunus mahaleb, Robledo-Arnuncio and Garcia, 2007). These discrepancies are consistent with life history traits of the species and suggest that seed dispersal in beech is primarily mediated by gravity and small rodents, as compared to fleshy-fruit species where dispersal is assisted primarily by birds but also bigger mammals (Jordano et al., 2007).

In contrast to seed dispersal within site, seed immigration rates in European beech $\left(m_{s}=27 \%\right.$ on average) indicate that "longdistance" seed dispersal events (i.e. from outside the study site) are not negligible in the investigated sites. This was not the case for Japanese beech where we found a null seed migration rate. High rates of seed immigration could be associated with disturbances, as the three European beech sites all have a more recent history of perturbation than the Japanese beech sites, with recent expansion in FS1 and FS2, but also strong canopy opening in FS3 due to a storm occurred in 1999. However, the estimated values for immigration rates should be considered with caution, because they are also probably affected by different experimental biases: (1) mortality/logging of adults within the studied site could result in false migration events, as supported by high $m_{s}$-values observed in the saplings $\left(m_{s}=48 \%\right.$ ) compared to young seedlings ( $m_{s}=16 \%$ for see Bontemps et al., unpublished) and (2) genotyping error and null alleles could also result in false parentage exclusion and overestimated migration rates.

Regarding pollen dispersal, the results for Japanese beech suggest greater abilities of pollen versus seed dispersal, with both a higher mean dispersal distance $\left(\delta_{p}=79.04 \mathrm{~m}\right.$ versus $\left.\delta_{s}=12.44 \mathrm{~m}\right)$, and a fatter-tailed kernel ( $b_{p}=0.31$ versus $\left.b_{s}=1.06\right)$. Pollen dispersal parameters $\left(\delta_{p}\right.$ and $b_{p}$ ) for European beech should be considered with caution as they were estimated based only on seedling for whom at least one compatible parent pair was found within the study site. Few seedlings met this requirement, as shown by the high $m_{s}$ and $m_{p}$-values. 


\subsection{Comparison of historical and contemporary estimates of gene} flow

We computed axial root-mean-squared $\sigma_{p-r t}$ and $\sigma_{s-r t}$ from our contemporary estimates of mean distance of seed and pollen dispersal $\left(\delta_{s}\right.$ and $\delta_{p}$, Table 4$)$ using Eq. (6). This provided real-time, total gene flow estimates $\left(\sigma_{r t}\right)$ ranging between 19 and $142 \mathrm{~m}$ in European beech, and equal to $71 \mathrm{~m}$ in Japanese beech (Table 4). These are probably underestimates as they do not account for immigration from outside the study site. Interestingly, contemporary $\left(\sigma_{r t}\right)$ and historical $\left(\sigma_{\mathrm{e}}\right)$ estimates of gene flow fell within the same order of magnitude (a few tens of meters). In FS2 and FC $\sigma_{r t}$ fell within the confidence interval of $\sigma_{\mathrm{e}}$ estimated when assuming $d_{\mathrm{e}}=d_{\mathrm{obs}} / 10$. In FS1 and FS3 contemporary estimates of gene flow tended to be lower than historical estimates, suggesting a possible recent reduction in effective dispersal abilities. However it is difficult establish whether the observed discrepancy (1) is truly significant, (2) is due to the assumptions and statistical specificities of the two approaches or (3) whether the range of gene dispersal has actually changed. These results highlight the caution required when drawing quantitative conclusions from the comparison of contemporary and historical estimates because they both rely on different assumptions that affect the accuracy and precision of estimates in uncomparable way. Contemporary estimates may suffer low bias at the scale of the study site, but they may underestimate longdistance dispersal (Oddou-Muratorio and Klein, 2008). By contrast, historical estimates have minimum precision, and suffer from high general uncertainty for the value of the effective density $d_{\mathrm{e}}$ value.

The comparison of historical versus contemporary estimates sheds some light on the different components of gene flow contributing to the development of SGS. For instance, the increasing SGS/decreasing $d_{\mathrm{e}} \sigma_{e}$ product observed from adults to seedlings in Japanese beech is consistent with the restricted dispersal distances estimated using the contemporary approach, and in particular with the low pollen and seed migration rates $\left(m_{s} \approx 0, m_{p}=40 \%\right)$. By contrast, in European beech, higher pollen and seed migration rates ( $m_{s} \approx 27 \%, m_{p}=68 \%$ ) may explain why SGS does not increase in the seedling cohort despite restricted seed and pollen dispersal distances within the study site. Thus, besides variation in the effective population density discussed above, our results suggest that longdistance seed and/or pollen flow can have a strong impact in the building of SGS within beech populations.

Finally, the roughly similar measures of gene flow obtained using historical or contemporary estimates in this study and others (Oddou-Muratorio and Klein, 2008) may provide guidance for researchers interested in measuring gene flow to select one of the two approaches, depending on the resources or constraints of the study. Historical approaches are clearly less costly in term of sampling effort since they do not require exhaustive sampling and mapping. They can thus be useful in providing some preliminary estimates of total gene flow, particularly if the sampling design includes different cohorts among which estimates can be compared. By contrast, contemporary estimates are clearly more costly to obtain since they require exhaustive sampling of the parental population within a given area, as well as, ideally, measures of covariates of fecundity for these trees. Conversely, they yield a much more detailed description of gene flow, and in particular they allow the relative importance of seed versus pollen-mediated dispersal and of long versus short distance dispersal to be gauged. A main conclusion of this study is that the combination of both historical and contemporary approaches may be the only solution when the objective is to detect recent changes in effective dispersal ability or to gauge the influence of the different components of gene flow in the building of SGS.

\subsection{Perspectives on beech's response to climate change and management of genetic resources}

Estimates of seed dispersal in European and Japanese beech (a few tens of meters/generation) obtained in this study are roughly one order of magnitude below what would be needed for beech to track 21st-century global warming (hundreds of meters for the next generation). This substantial discrepancy also supports recent re-interpretation of post-glacial expansion rates during the early Holocene in the light of chloroplast DNA surveys (McLachlan et al., 2005; Magri, 2008). Rather than rapid range expansions from well-established refugees at rates of 100-1000 m/year, molecular studies suggested that for different tree species including beech post-glacial recolonisation relied on a mosaic of sparse, small populations scattered in multiple regions closer to modern range limit than previously thought. These authors proposed that average post-glacial migration rates of beech may have been slower than those inferred from fossil pollen, and closer to those estimated in this study. However, one cannot rule out that rare events of long-distance seed dispersal still contributed to post-glacial recolonisation, and may contribute to future response to climate change. The importance of these long-distance dispersal events is notoriously complicated to quantify, and requires to be addressed at spatial and temporal scales larger than in the present study.

Assuming that gene migration may favour a rapid adaptive response to the ongoing climate change by mixing or adding well adapted genetic material to poorly adapted gene pools, this study suggests several ways in which forest management may enhance the beneficial effect of migration. Stand regeneration is clearly a crucial phase: to increase genetic diversity at local scale, management should (1) favour a regular spatial distribution of selected seed trees (i.e. avoid clumping), (2) spread the recruitment process across several different years, even in masting species, and (3) favour regeneration plots both close to and far from the seed trees. Note however that the final outcome of the interaction between gene flow and selection in the response of beech population to global change cannot be addressed without additional studies, comparing core and marginal populations, either at the front or at the rear edge of distribution range, and evaluating simultaneously the potential for genetic adaptation and gene flow.

\section{Acknowledgements}

We thank A. Roig and B. Jouaud (INRA Avignon) for sampling, genotyping and managing of lab work in European beech. We also thank F. Rei, O. Gilg, N. Thurion and F. Jean (UEFM, Avignon), as well P. Legroux, A. Nassau, F. Bonne, T. Paul and J.P. Lemaire (UEFL, Nancy) for field work (mapping and in situ measurement). For the study in F. crenata, we thank K. Maruyama, J. Takahashi, M. Tomita, N. Ueno, M. Takahashi, and K. Seiwa. This study was funded by the French Bureau des Ressources Génétiques (BRG grant AIP 223 No. 88-2003-2004), EVOLTREE NoE (BEECH project), and ECOGER project Bases d'une gestion durable des forêts mélangées (2005-2008).

\section{References}

Abramowitz, M. Stegun, IA. 1964. Handbook of Mathematical Functions with Formulas, Graphs, and Mathematical Tables Nat. Bur. Standards, Appi. Math. Ser. 55. U.S. Government Printing Office, Washington, DC.

Alleaume-Benharira, M., Pen, I.R., Ronce, O., 2006. Geographical patterns of adaptation within a species' range: interactions between drift and gene flow. J. Evol Biol. 19, 203-215

Asuka, Y., Tani, N., Tsumura, Y., Tomaru, N., 2004. Development and characterization of microsatellite markers for Fagus crenata Blume. Mol. Ecol. Notes 4, 101-103.

Asuka, Y., Tomaru, N., Munehara, Y., Tani, N., Tsumura, Y., Yamamoto, S., 2005. Halfsib family structure of Fagus crenata saplings in an old-growth beech-dwarf bamboo forest. Mol. Ecol. 14, 2565-2575. 
Austerlitz, F., Dick, C.W., Dutech, C., Klein, E.K., Oddou-Muratorio, S., Smouse, P.E., Sork, V.L., 2004. Using genetic markers to estimate the pollen dispersal curve. Mol. Ecol. 13, 937-954.

Bacles, C.F.E., Burczyk, J., Lowe, A.J., Ennos, R.A., 2005. Historical and contemporary mating patterns in remnant populations of the forest tree Fraxinus excelsior. Evolution 59, 979-990.

Bullock, J.M., Nathan, R., 2008. Plant dispersal across multiple scales: linking models and reality. J. Ecol. 96, 567-568.

Burczyk, J., Adams, W.T., Birkes, D.S., Chybicki, I.J., 2006. Using genetic markers to directly estimate gene flow and reproductive success parameters in plants on the basis of naturally regenerated seedlings. Genetics 173, 363-372.

Chybicki, I.J., Burczyk, J., 2009. Simultaneous estimation of null alleles and inbreeding coefficients. J. Hered. 100, 106-113.

Chybicki, IJ., Trojankiewicz, M., Oleksa, A., Dzialuk, A., Burczyk, J., 2009. Isolationby-distance within naturally established populations of European beech (Fagus sylvatica). Botany $87,791-798$.

Clark, J.S., 1998. Why trees migrate so fast: confronting theory with dispersal biology and the paleorecord. Am. Nat. 152, 204-224.

Davis, M.B., Shaw, R.G., 2001. Range shifts and adaptive responses to Quaternary climate change. Science 292, 673-679.

Dunphy, B., Hamrick, J.L., 2005. Gene flow among established Puerto Rican populations of the exotic tree species, Albizia lebbeck. Heredity 94, 418-425.

Dutech, C., Sork, V.L., Irwin, A.J., Smouse, P.E., Davis, F.W., 2005. Gene flow and fine-scale genetic structure in a wind-pollinated tree species, Quercus lobata (Fagaceaee). Am. J. Bot. 92, 252-261.

Epperson, B.K., 1992. Spatial structure of genetic variation within populations of forest trees. New Forests 6, 257-278.

Gonzalez-Martinez, S.C., Burczyk, J., Nathan, R., Nanos, N., Gil, L., Alia, R., 2006. Effective gene dispersal and female reproductive success in Mediterranean maritime pine (Pinus pinaster Aiton). Mol. Ecol. 15, 4577-4588.

Hampe, A., Petit, R.J., 2005. Conserving biodiversity under climate change: the rear edge matters. Ecol. Lett. 8, 461-467.

Hardy, O.J., Vekemans, X., 2002. SPAGeDi: a versatile compute program to analyse spatial genetic structure at the individual or population levels. Mol. Ecol. Notes 2, 618-620.

Hardy, O.J., Maggia, L., Bandou, E., Breyne, P., Caron, H., Chevallier, M.H., Doligez, A., Dutech, C., Kremer, A., Latouche-Hallé, C., Troispoux, V., Veron, V., Degen, B., 2006. Fine-scale genetic structure and gene dispersal inferences in ten Neotropical tree species. Mol. Ecol. 15, 559-571.

Hanaoka, S., Yuzurihara, J., Asuka, Y., Tomaru, N., Tsumura, Y., Kakubari, Y., Mukai, Y., 2007. Pollen-mediated gene flow in a small, fragmented natural population of Fagus crenata. Botany 85, 404-413.

Jensen, T.S., 1985. Seed-seed predator interactions of European beech, Fagus silvatica and forest rodents, Clethrionomys glareolus and Apodemus flavicollis. Oikos 44, $149-156$.

Jones, F.A., Chen, J., Weng, G.-J., Hubbell, S.P., 2005. A genetic evaluation of seed dispersal in the Neotropical tree Jacaranda copaia (Bignoniaceae). Am. Nat. 166, 543-555.

Jordano, P., Garcia, C., Godoy, J.A., Garcia-Castano, J.L., 2007. Differential contribution of frugivores to complex seed dispersal patterns. Proc. Natl. Acad. Sci. U.S.A. 104, 3278-3282.

Jump, A.S., Penuelas, J., 2007. Extensive spatial genetic structure revealed by AFLP but not SSR molecular markers in the wind-pollinated tree, Fagus sylvatica. Mol. Ecol. 16, 925-936.

Jump, A.S., Mátyás, C., Peñuelas, J., 2009. The altitude-for-latitude disparity in the range retractions of woody species. Trends Ecol. Evol. 24, 694-701.

Krouchi, F., Derridj, A., Lefevre, F., 2004. Year and tree effect on reproductive organisation of Cedrus atlantica in a natural forest. For. Ecol. Manage. 197, 181-189.

Kalinowski, S., Taper, M., 2006. Maximum likelihood estimation of the frequency of null alleles at microsatellite loci. Conserv. Genet. 7, 991-995.

Kramer, K., Buiteveld, J., Forstreuter, M., Geburek, T., Leonardi, S., Menozzi, P., Povillon, F., Schelhaas, M.J., Teissier du Cros, E., Vendramin, G.G., Werf, D.C., 2008 Bridging the gap between ecophysiological and genetic knowledge to assess the adaptive potential of European beech. Ecol. Modell. 216, 333-353.

Leblois, R., Rousset, F., Estoup, A., 2004. Influence of spatial and temporal heterogeneities on the estimation of demographic parameters in a contin- uous population using individual microsatellite data. Genetics 166, 1081 1092.

Lenormand, T., 2002. Gene flow and the limits to natural selection. Trends Ecol. Evol 17, 183-189.

Leonardi, S., Menozzi, P., 1996. Spatial structure of genetic variability in natural stands of Fagus sylvatica L. (beech) in Italy. Heredity 77, 359-368.

Loiselle, B.A., Sork, V.L., Nason, J., Graham, C., 1995. Spatial genetic structure of a tropical understory shrub, Psychotria officinalis (Rubiaceae). Am. J. Bot. 82 $1420-1425$.

Magri, D., 2008. Patterns of post-glacial spread and the extent of glacial refugia of European beech (Fagus sylvatica). J. Biogeogr. 35, 450-463.

Manel, S., Gaggiotti, O.E., Waples, R.S., 2005. Assignment methods: matching biological questions with appropriate techniques. Trends Ecol. Evol. 20, 136-142.

McLachlan, J.S., Clark, J.S., Manosa, P.S., 2005. Molecular indicators of tree migration capacity under rapid climate change. Ecology 86, 2088-2098.

Meagher, T.R., 1986. Analysis of paternity within a natural population of Chamaelirium luteum. I. Identification of most-likely male parents. Am. Nat. 128, 199-215.

Merzeau, D., Comps, B., Thiébaut, J.L., 1994. Estimation of Fagus sylvatica L. mating system parameters in natural populations. Ann. For. Sci. 51, 163-173.

Morgan, M.T., Conner, J.K., 2001. Using genetic markers to directly estimate male selection gradients. Evolution 55, 272-281.

Oddou-Muratorio, S., Klein, E.K., 2008. Comparing direct vs. indirect estimates of gene flow within a population of a scattered tree species. Mol. Ecol. 17 2743-2754.

Oddou-Muratorio, S., Klein, E.K., Austerlitz, F., 2005. Pollen flow in the wildservice tree, Sorbus torminalis (L.) Crantz. II. Pollen dispersal and heterogeneity in mating success inferred from parent-offspring analysis. Mol. Ecol. 14, 44414452.

Oddou-Muratorio, S., Vendramin, G.G., Buiteveld, J., Fady, B., 2009. Population estimators or progeny tests: what is the best method to assess null allele frequencies at SSR loci? Conserv. Genet. 10, 1343-1347.

Otero-Arnaiz, A., Casas, A., Hamrick, J.L., 2005. Direct and indirect estimates of gene flow among wild and managed populations of Polaskia chichipe, an endemic columnar cactus in Central Mexico. Mol. Ecol. 14, 4313-4322.

Parker, K.C., Hamrick, J.L., Parker, A.J., Nason, J.D., 2001. Fine-scale genetic structure in Pinus clausa (Pinaceae) populations: effects of disturbance history. Heredity 87, 99-113.

Pastorelli, R., Smulders, M.J.M., Van't Westende, W.P.C., Vosman, B., Giannini, R. Vetori, C., Vendramin, G.G., 2003. Characterization of microsatellite markers in Fagus sylvatica L. and Fagus orientalis Lipsky. Mol. Ecol. Notes 3, 76-78.

Robledo-Arnuncio, J.J., Garcia, C., 2007. Estimation of the seed dispersal kernel from exact identification of source plants. Mol. Ecol. 16, 5098-5109.

Ronce, O., 2007. How does it feel to be like a rolling stone? Ten questions about dispersal evolution. Ann. Rev. Ecol. Evol. Syst. 38, 231-253.

Rousset, F., 2000. Genetic differentiation between individuals. J. Evol. Biol. 13, 58-62.

Schweizer, M., Excoffier, L., Heckel, G., 2007. Fine-scale genetic structure and dispersal in the common vole (Microtus arvalis). Mol. Ecol. 16, 2463-2473.

Smouse, P.E., Sork, V.L., 2004. Measuring pollen flow in forest trees: an exposition of alternative approaches. For. Ecol. Manage. 197, 21-38.

Sykes, M.T., Prentice, I.C., Cramer, W., 1996. A bioclimatic model for the potential distributions of north European tree species under present and future climates. J. Biogeogr. 23, 203-233.

Takahashi, M., Mukouda, M., Koono, K., 2000. Differences in genetic structure between two Japanese beech (Fagus crenata Blume) stands. Heredity 84 103-115.

Tanaka, K., Tsumura, Y., Nakamura, T., 1999. Development and polymorphism of microsatellite markers for Fagus crenata and the closely related species, F. japonica. Theor. Appl. Genet. 99, 11-15.

Tomita, M., Hirabuki, Y., Seiwa, K, 2002. Post-dispersal changes in the spatial distribution of Fagus crenata seeds. Ecology 83, 1560-1565.

Vekemans, X., Hardy, O.J., 2004. New insights from fine-scale spatial genetic structure analyses in plant populations. Mol. Ecol. 13, 921-935.

Vornam, B., Decarli, N., Gailing, O., 2004. Spatial distribution of genetic variation in a natural beech stand (Fagus sylvatica L.) based on microsatellite markers. Conserv. Genet. 5, 561-570. 